\title{
O EMPREGO DE QUITOSANA QUIMICAMENTE MODIFICADA COM ANIDRIDO SUCCÍNICO NA ADSORÇÃO DE AZUL DE METILENO
}

\author{
Ilauro S. Lima, Emerson S. Ribeiro e Claudio Airoldi* \\ Instituto de Química, Universidade Estadual de Campinas, CP 6154, 13084-971 Campinas - SP, Brasil
}

Recebido em 13/4/05; aceito em 29/8/05; publicado na web em 8/2/06

\begin{abstract}
THE USE OF CHEMICALLY MODIFIED CHITOSAN WITH SUCCINIC ANHYDRIDE IN THE METHYLENE BLUE ADSORPTION. The adsorption capacity of $\alpha$-chitosan and its modified form with succinic anhydride was compared with the traditional adsorbent active carbon by using the dye methylene blue, employed in the textile industry. The isotherms for both biopolymers were classified as SSA systems in the Giles model, more specifically in L class and subgroup 3. The dye concentration in the supernatant in the adsorption assay was determined through electronic spectroscopy. By calorimetric titration thermodynamic data of the interaction between methyene blue and the chemically modified chitosan at the solid/liquid interface were obtained. The enthalpy of the dye/chitosan interaction gave $2.47 \pm 0.02 \mathrm{~kJ} \mathrm{~mol}^{-1}$ with an equilibrium constant of $7350 \pm 10$ and for the carbon/dye interaction this constant gave $5951 \pm 8$. The spontaneity of these adsorptions are reflected by the free Gibbs energies of $-22.1 \pm 0.4$ and $-21.5 \pm 0.2 \mathrm{~kJ} \mathrm{~mol}^{-1}$, respectively, found for these systems. This new adsorbent derived from a natural polysaccharide is as efficient as activated carbon. However $97 \%$ of the bonded dye can be eluted by sodium chloride solution, while this same operation elutes only $42 \%$ from carbon. Chitosan is efficient in dye removal with the additional advantage of being cheap, non-toxic, biocompatible and biodegradable.
\end{abstract}

Keywords: chitosan; succinic anhydride; methylene blue.

\section{INTRODUÇÃO}

Os polissacarídeos denominados $\beta(1 \rightarrow 4) 2$-acetamida-2-desoxiD-glicopiranose e $\beta(1 \rightarrow 4) 2$-amino-2-desoxi-D-glicopiranose são conhecidos pelas denominações quitina e quitosana, respectivamente. São biopolímeros interligados por ligações $\beta$-glicosídicas, sendo que em ambos os tipos de estruturas não há predominância de quaisquer espécies monoméricas. Assim, ambas as formas coexistem na natureza em uma estrutura polimérica, com grau parcial de desacetilação ${ }^{1}$, constituindo um copolímero. A quitina nativa possui em torno de $10 \%$ de grupos aminos livres ${ }^{2}$, enquanto que a forma desacetilada apresenta, em média, um teor desses grupos ${ }^{1,2}$ não superior a $97 \%$.

Quanto à natureza estrutural desses materiais, tem-se conhecimento de que a quitina pode se apresentar sob as formas $\alpha, \beta$ e $\gamma$. Entretanto, a última é ainda pouco estudada, provavelmente por conter percentuais predominantes das formas $\alpha$ e $\beta$ na sua constituição. Tanto a quitina natural como a quitosana apresentam alto grau de associação com proteínas, formando as glicoproteínas, com percentual que varia de 20 a $50 \%$ nos artrópodes ${ }^{3}$. A quitina faz parte da constituição da estrutura material e protetora dos insetos, animais marinhos e microrganismos celulares. Em processo laboratorial, a quitina é obtida a partir da abertura de anel do grupo exazolina de um derivado de açúcar ou por biossíntese, a partir da glicose em processo enzimático ${ }^{3}$.

Um grande número de modificações químicas através de rotas homogênea e heterogênea pode ser realizado no anel glicopiranosídeo da quitina e quitosana, conferindo aplicabilidades aos novos biopolímeros ${ }^{4,5}$. Na rota homogênea é imprescindível solubilizar a quitina e a quitosana com soluções de cloreto de lítio em N,N'dimetilacetamida e ácido acético $1,70 \mathrm{~mol} \mathrm{dm}^{-3}$, respectivamente, o que a rota heterogênea ${ }^{6}$ não requer.

*e-mail: airoldi@iqm.unicamp.br
A modificação química da quitosana com anidridos orgânicos conduz à acetilação do grupo amino, ligado ao carbono 2 do anel glicopiranosídeo, em um processo denominado de $\mathrm{N}$-acetilação. Porém, quando ocorre uma reação de regiosseletividade, com ataque no substituinte ligado ao carbono 6, a reação é chamada de Oacilação, podendo ser empregado, neste caso, como material de partida tanto a quitina como a quitosana?

As modificações químicas da quitosana podem ocorrer de forma concomitante através dos carbonos ${ }^{8} 2$ e 6 , enquanto que em etapas a reação é direcionada primeiramente ao carbono 2, seguido do carbono 9 , cujas modificações são denominadas de $\mathrm{N}$-acetilação.

Do ponto de vista operacional existe certa facilidade no uso da rota homogênea em realizar reações do tipo N,O-acetilações de forma simultânea nas posições 3 e 6 para a quitina e 2, 3 e 6 para a quitosana ${ }^{10}$. Algumas possibilidades de obtenção de novos materiais a partir das rotas descritas podem ser melhores visualizadas na Figura 1. Em se tratando de reatividade, os grupos pendentes ligados aos carbonos do anel obedecem à ordem decrescente $\mathrm{C}_{2}>\mathrm{C}_{6}>$ $\mathrm{C}_{3}$, referentes ao grupo amino da quitosana, ao grupo hidroxil primário de caráter mais instável e ao grupo hidroxil secundário, respectivamente. Nesse último centro reativo é requerido um agente desprotonante para torná-lo pré-disponível à reação subseqüente ${ }^{11}$.

\section{APLICAÇÕES}

A quitina é apenas superada pela celulose em abundância natural em nosso planeta. Dentre as fontes de biopolímeros renováveis, a quitina destaca-se por ser facilmente obtida, não tóxica, biocompatível e biodegradável, porém, por apresentar o grupo amino acetilado, comporta-se com baixa capacidade de sorção ${ }^{1,4,5}$. Por isso mesmo, torna-se indispensável o tratamento químico para transformá-la na forma desacetilada, cujo grupo amino livre da quitosana possui capacidade em adsorver metais pesados ${ }^{12-14}$ e corantes ${ }^{15}$. Neste particular, o azul de metileno, representado na Figura 2, é o menos utiliza- 

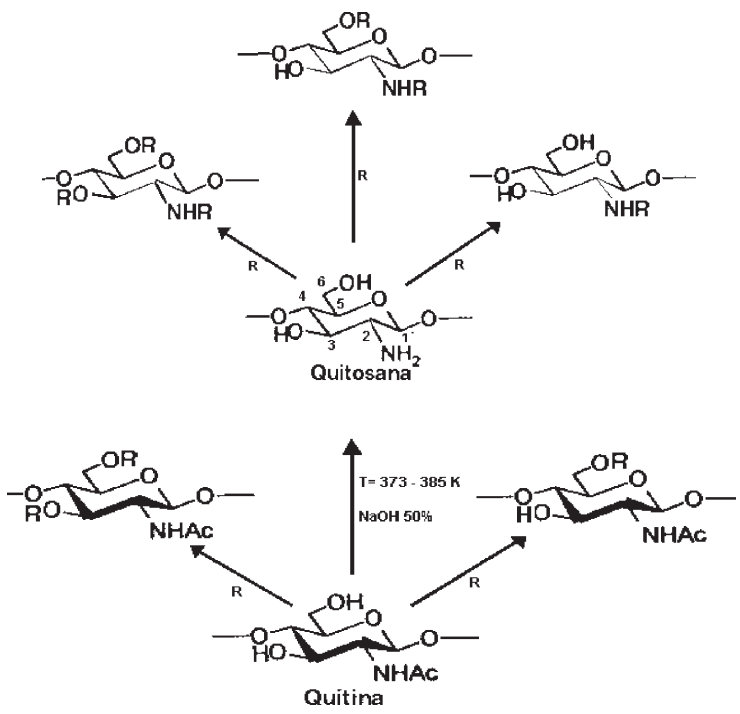

Figura 1. Tipos de modificações químicas nos polissacarídeos quitina e quitosana, sendo $R$ um radical orgânico ou inorgânico

do para testar a capacidade adsorvente ${ }^{16}$. Ressalta-se que a pesquisa em adsorção foi ampliada a vários campos de atividades profissionais, como medicina, agricultura, biotecnologia, odontologia, indústrias alimentícia e farmacêutica, e na ciência de modo geral ${ }^{3}$. Em se tratando de aplicações, a quitosana e seus derivados refletem um exemplo bem sucedido do uso de materiais naturais, que contemplam várias áreas ${ }^{17}$, como mostra a Tabela 1.

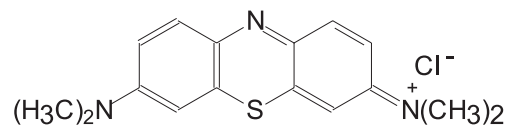

Figura 2. Forma estrutural do corante azul de metileno

\section{MICROCALORIMETRIA}

Os efeitos interativos de quaisquer espécies ácidas com os possíveis centros básicos existentes nas estruturas dos biopolímeros quitina e quitosana podem ser acompanhados através da técnica de titulação calorimétrica em solução. As vantagens associadas estão relacionadas à sensibilidade instrumental, que permite efetivar medidas de quaisquer mudanças físicas ou químicas que acontecem no sistema. Além disso, os efeitos térmicos podem ser obtidos em sistemas não transparentes e com miligramas dos materiais, sendo que os sinais são ampliados e registrados. Os instrumentos com estas características, denominados microcalorímetros, têm uso em várias atividades tanto em sistemas inorgânicos ${ }^{28}$, orgânicos ${ }^{1} \mathrm{e}$ microrganismos de $\operatorname{solos}^{29}$.

Os efeitos térmicos liberados e/ou absorvidos em um dado sistema, químico, físico, ou biológico, são proporcionais à quantidade de matéria envolvida ${ }^{1,28}$. A potência térmica $(\mathrm{P})$ de uma dada interação é medida sob pressão constante e o efeito térmico de interação $(\mathrm{Q})$ pode ser determinado ${ }^{1,28}$, como na Equação 1:

$\mathrm{P}=\mathrm{d}(\Delta \mathrm{Q}) / \mathrm{dt}$

Do ponto de vista experimental, a etapa calorimétrica requer o conhecimento dos componentes envolvidos na reação e da quantidade que participa na interação, traduzido por quantidade de matéria $(\mathrm{N})$, permitindo assim o cálculo da entalpia $\left(\Delta \mathrm{H}^{\circ}\right)$ do processo. $\mathrm{Na}$ titulação, a constante de equilíbrio $(\mathrm{K})$ do sistema e a respectiva entalpia são obtidas simultaneamente, o que possibilita a determinação da energia livre de Gibbs $\left(\Delta \mathrm{G}^{\circ}\right)$ e a entropia ${ }^{1}\left(\Delta \mathrm{S}^{\circ}\right)$, através das Equações 2 a 4:

$$
\begin{aligned}
& \Delta \mathrm{H}^{\circ}=\mathrm{Q} / \mathrm{N} \\
& \Delta \mathrm{G}^{\mathrm{o}}=-\mathrm{RT} \ln \mathrm{K} \\
& \Delta \mathrm{G}^{\mathrm{o}}=\Delta \mathrm{H}^{\mathrm{o}}-\mathrm{T} \Delta \mathrm{S}^{\mathrm{o}}
\end{aligned}
$$

Na titulação, o procedimento experimental consiste em adicionar através de uma microsseringa, sucessivos volumes de solução titulante, previamente termostatizada, ao titulado contido no vaso calorimétrico, sempre sob agitação conveniente. O efeito térmico total de interação é então determinado pelo somatório dos efeitos térmicos obtidos durante a titulação ${ }^{1,28}$.

O presente estudo enfoca aspectos relacionados com o processo de adsorção do corante azul de metileno sobre a superfície da quitosana na forma $\alpha$ e, também, quando modificada quimicamente com anidrido succínico. O poder de adsorção foi comparado com o do carvão ativo, que é um adsorvente tradicionalmente usado na indústria de corantes ${ }^{30}$.

\section{PARTE EXPERIMENTAL}

\section{Obtenção da quitosana}

A quitina do tipo $\alpha$ (Kito Química Fina), extraída da casca de caranguejo, foi triturada em moinho de facas com navalha para produzir partículas de diâmetro $0,5 \mathrm{~cm}$, as quais foram peneiradas para se obter granulometria entre 80-200 mesh. Na desacetilação 3,0 g de quitina contida em um frasco de Teflon foram misturadas com $600 \mathrm{~cm}^{3}$ de hidróxido de sódio $12,0 \mathrm{~mol} \mathrm{dm}^{-3}$ e aquecidas por $2 \mathrm{~h}$ à temperatura de $383 \mathrm{~K}$, para produzir o biopolímro $\alpha$-Qtan.

Tabela 1. Aplicações dos biopolímeros quitina e quitosana e seus derivados

\begin{tabular}{lll}
\hline Quitina, Quitosana e derivados & Aplicações & Ref. \\
\hline Quitosana & Tratamento periodontal & 18 \\
Quitosana & Tratamento gastrointestinal para cães & 19 \\
Quitosana & Purificação da água & 20 \\
Oligômero de quitosana & Agente antimicrobial & 21 \\
Quitina funcionalizada com 1-nitroso-3,6-disulfo-2-naphtolato & Pré-concentração de Co(II) e Ni(II) \\
Esfera híbrida de quitosana-alginato & Adsorção de íons de metais divalentes \\
Quitosana e quitina & Adsorção de ácido húmico \\
Eletrodo de platina quimicamente modificado com quitosana & Detecção da sequiência específica do DNA \\
Quitosana intercalada na montmorilonita sódica & Biossensor para ânions \\
Complexo alginato-quitosana & Agente coagulante para tratamento do queijo cheddar \\
\hline
\end{tabular}




\section{Funcionalização}

Uma amostra de 3,0 g de quitosana foi agitada em 70,0 $\mathrm{cm}^{3}$ de solução 1,20 mol dm${ }^{-3}$ de cloreto de lítio em N,N'-dimetilacetamida por $15 \mathrm{~min}$, em balão de duas bocas, à temperatura de $298 \pm 1 \mathrm{~K}$. A seguir, 1,20 $\mathrm{g}$ de anidrido succínico dissolvidos no mesmo solvente foram acrescentados à mistura, agitando-se por mais $30 \mathrm{~min}$. Seguiu-se à adição de $2,8 \mathrm{~cm}^{3}$ de trietilamina e a mistura foi agitada por $24 \mathrm{~h}$. Após adição de $30 \mathrm{~cm}^{3}$ de metanol, a agitação continuou por mais $30 \mathrm{~min}$. Ao término da reação, o conteúdo do balão foi transferido para um béquer contendo $100 \mathrm{~cm}^{3}$ de água desionizada, ao qual se adicionou uma solução de ácido clorídrico $2,0 \mathrm{~mol} \mathrm{dm}^{-3}$. À suspensão formada foram acrescentadas três gotas da solução $0,10 \mathrm{~mol} \mathrm{dm}^{-3} \mathrm{de} \mathrm{Na}_{2} \mathrm{HPO}_{4}$ para ajuste de $\mathrm{pH}$ e força iônica do meio, sendo seguida da diálise em membrana bovina, contra água desionizada por três dias, cuja membrana foi preparada seguindo procedimento recomendado ${ }^{31}$. Finalmente, o sólido foi filtrado em funil de Buchner e seco em linha de vácuo por $8 \mathrm{~h}$, recebendo a denominação $\alpha$-Qtan-2,6.

\section{Adsorção}

A adsorção do azul de metileno em quitosana $\alpha$-Qtan2,6 e carvão ativo foi feita sempre em duplicata, através do método de batelada. Foram utilizados frascos previamente providos de concentrações diferentes e crescentes do corante dissolvido em água, sendo que em todos os experimentos o volume final da solução ${ }^{1,4,5,12}$ foi sempre mantido em $50,0 \mathrm{~cm}^{3}$, para uma concentração inicial do corante de $5,54 \mathrm{mmol} \mathrm{dm}^{-3}$. Em todos os frascos foram adicionados cerca de $50 \mathrm{mg}$ do adsorvente e agitados em sistema orbital à $298 \pm 1 \mathrm{~K}$. Após $4 \mathrm{~h}$ foram retiradas alíquotas das soluções sobrenadantes para posterior análise do conteúdo do soluto em solução, para determinar a quantidade de matéria $\left(\mathrm{N}_{\mathrm{f}}\right)$ adsorvida ${ }^{1,2,4,5}$.

$\mathrm{O}$ sólido submetido à adsorção do corante, tanto a quitosana como o carvão, foi filtrado e exaustivamente lavado com solução eluente de cloreto de sódio $0,10 \mathrm{~mol} \mathrm{dm}^{-3}$, até que o líquido de lavagem permanecesse incolor. O teor de corante livre foi medido na solução filtrada em espectrofotômetro, tendo como branco a solução de cloreto de sódio.

\section{Medidas de pH}

As medidas de $\mathrm{pH}$ das soluções contendo o corante com e sem as matrizes carvão ativo ou $\alpha$-Qtan-2,6, bem como a determinação da matriz $\alpha$-Qtan-2,6 em água desionizada, foram obtidas à temperatura de $298 \pm 1 \mathrm{~K}$ em triplicata e sob agitação. Para as concentrações de corante utilizadas, na faixa de $10^{-4}$ a $10^{-5}$ os valores foram 6,0 e 6,3, respectivamente. Com o carvão ativado e com a quitosana o $\mathrm{pH}$ obtido foi 5,6 e com a quitosana modificada em água ou em corante, o valor foi 5,5 .

\section{Calorimetria}

O estudo calorimétrico das interações do azul de metileno com o biopolímero $\alpha$-Qtan-2,6 e carvão ativado foi efetuado através três experimentos individuais, com determinações em duplicatas dos efeitos térmicos resultantes à temperatura de 298,15 \pm 0,20 K. Assim, o efeito interativo líquido resulta da subtração dos efeitos de diluição, conforme Equação 5:

$\mathrm{Q}_{\text {resultante }}=\mathrm{Q}_{\text {reação }}-\left(\mathrm{Q}_{\text {diluição }}+\mathrm{Q}_{\text {hidrataçăo }}\right)$

O efeito térmico resultante ${ }^{1,4}$ foi obtido por adições sucessivas de $10 \mu \mathrm{L}$ de solução titulante (Sol), azul de metileno ou água, através de microsseringa acoplada a uma cânula de ouro, sobre uma suspensão contendo cerca de $50 \mathrm{mg}$ do biopolímero (Bpol) em 12,0 $\mathrm{cm}^{3}$ de água desionizada. As etapas envolvidas na titulação calorimétrica podem ser representadas pelas Equações 6 a 8:

$\mathrm{Bpol}_{\text {(aq) }}+\mathrm{Sol}_{\text {(aq) }}=\mathrm{Bpol} . \mathrm{Sol}_{(\mathrm{aq})} ; \quad \mathrm{Q}_{\mathrm{r}}$

$\mathrm{Bpol}_{(\mathrm{aq})}+\mathrm{nH}_{2} \mathrm{O}_{(\mathrm{aq})}=\mathrm{Bpol}_{\mathrm{nH}} \mathrm{O}_{(\mathrm{aq})} ; \quad \mathrm{Q}_{\mathrm{h}}$

$\mathrm{Sol}{ }_{(\mathrm{aq})}+\mathrm{nH}_{2} \mathrm{O}_{(\mathrm{aq})}^{(\mathrm{aq})}=\mathrm{Sol}_{2} \mathrm{nH}_{2} \mathrm{O}_{(\mathrm{aq})} ; \quad \mathrm{Q}_{\mathrm{d}}$

sendo $\mathrm{Q}_{\mathrm{r}}$ o efeito térmico resultante, $\mathrm{Q}_{\mathrm{d}} \mathrm{o}$ efeito térmico do adsorbato diluído em água e $\mathrm{Q}_{\mathrm{h}}$ o efeito térmico do adsorvente com a água.

\section{Caracterização}

Para a espectroscopia de absorção na região do infravermelho as amostras foram trituradas com brometo de potássio, sempre com $2 \%$ de amostra e prensadas sob a forma de pastilhas. Os espectros foram obtidos em espectrofotômetro Bomem, modelo MB, com 40 varreduras.

As medidas de área superficial foram realizadas em um equipamento Micromeritics flowsorb II. As amostras foram inicialmente aquecidas a $250 \mathrm{~K} \mathrm{e}$, em seguida, uma mistura gasosa de $10 \%$ de nitrogênio em hélio percorreu a amostra esfriada à temperatura do nitrogênio líquido.

As medidas de $\mathrm{pH}$ foram realizadas em aparelho da Micronal, modelo B474.

$\mathrm{O}$ estudo de adsorção em batelada foi realizado à temperatura de $298 \pm 1 \mathrm{~K}$ para três amostras de corante com e sem a presença da quitosana modificada quimicamente. As concentrações das soluções sobrenadantes foram determinadas em espectrofotômetro Beckman DU 640 a $660 \mathrm{~nm}$.

Os espectros de ressonância magnética nuclear de ${ }^{13} \mathrm{C}$ no estado sólido foram obtidos mediante espectrômetro AC300/P Brucker com ângulo mágico, operando em CP/MAS em 75,47 MHz, com tempo de relaxação de $4 \mathrm{~s}$ e tempo de contato de $1 \mathrm{~ms}$, não sendo necessário quaisquer tratamentos prévio das amostras.

$\mathrm{O}$ estudo termoquímico foi realizado com microcalorímetro isotérmico de condução de calor, modelo LKB 2277, TAM (Thermal Activity Monitor), interfaciado a um microcomputador.

\section{RESULTADOS E DISCUSSÃO}

Os biopolímeros $\alpha$-quitina e quimicamente modificados $\alpha$-Qtan e $\alpha$-Qtan-2,6 foram caracterizados por análise elementar, determinação de área superficial, espectroscopia na região do infravermelho e ressonância magnética do núcleo de carbono-13 no estado sólido. Os efeitos interativos provenientes das interações do biopolímero $\alpha$-Qtan-2,6 foram ensaiados com corante azul de metileno, com finalidade de comparar a capacidade de adsorção com o carvão ativado, que é comumente usado como adsorvente de corantes industriais.

Os resultados de análise elementar dos biopolímeros estão listados na Tabela 2, mostrando aumento dos percentuais dos ele-

Tabela 2. Análise elementar da quitina ( $\alpha$-Qt), quitosana ( $\alpha$-Qtan) e quitosana modificada com anidrido succínico nas posições 2 e 6 do anel glicopiranosídeo ( $\alpha$-Qtan2,6)

\begin{tabular}{lccc}
\hline Compostos & $\mathrm{C}(\%)$ & $\mathrm{H}(\%)$ & $\mathrm{N}(\%)$ \\
\hline$\alpha$-Qt & 27,85 & 3,64 & 4,36 \\
$\alpha$-Qtan & 41,54 & 6,15 & 6,36 \\
$\alpha$-Qtan2,6 & 39,66 & 5,98 & 5,78 \\
\hline
\end{tabular}


mentos quando é subtraído o grupo acetila da quitina, de acordo com o processo desacetilação, ocasionando um aumento dos grupos amino livres no biopolímero, o que se reflete na reatividade da quitosana. $\mathrm{O}$ teor de desacetilação pode ser determinado através das bandas de absorção em 1655 e $3450 \mathrm{~cm}^{-1}$, às quais estão associadas as carbonilas dos grupos $\mathrm{N}$-acetil remanescentes da quitina e hidroxila, respectivamente ${ }^{1,4}$. Os espectros da quitosana e da forma modificada nas posições 2 e 6 do anel glicopiranosídeo estão mostradas na Figura 3. A partir do espectro da quitosana foram obtidos os valores de absorbância de 0,054 e 0,037, que possibilitaram o cálculo do grau de desacetilação (GD), através da Equação 9, dando um teor de $80 \%$.

$\mathrm{GD}=97,67-\left[26,486\left(\mathrm{~A}_{1655} / \mathrm{A}_{3450}\right)\right]$

As bandas compreendidas entre 3300 e $3100 \mathrm{~cm}^{-1}$ são atribuídas ao agrupamento NH do acetamido em ligações de hidrogênio intermoleculares, que desaparecem após desacetilação da quitina, pois o grupo amido foi transformado em amina primária ${ }^{12}$.

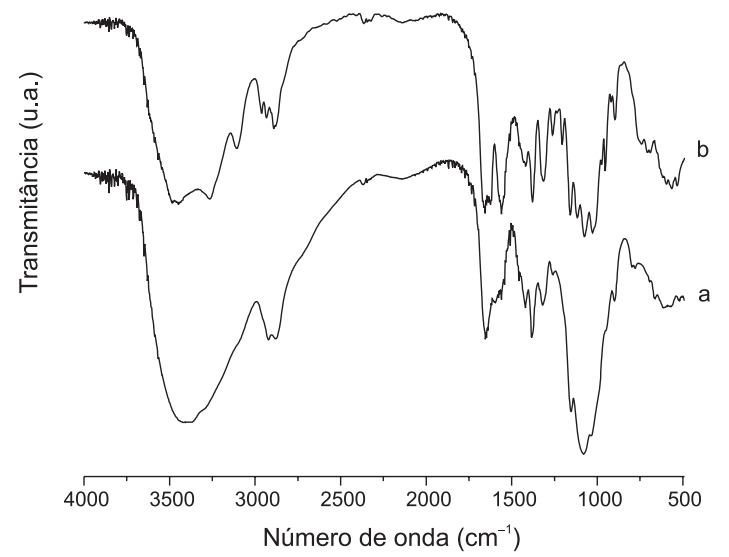

Figura 3. Espectroscopia na região do infravermelho para $\alpha$-quitosana (a) $e$ quitosana modificada com anidrido succínico (b)

A banda forte em $1051 \mathrm{~cm}^{-1}$ comum ao polissacarídeo de parti$\mathrm{da}$, às formas desacetilada e modificada é atribuída ao estiramento $\mathrm{C}-\mathrm{O}-\mathrm{C}$ do anel glicopiranosídeo ${ }^{32}$. A absorção em $1560 \mathrm{~cm}^{-1}$ é normalmente menos intensa no espectro da quitosana quando comparado com o da quitina, devido ao processo de desacetilação. No entanto, é quase imperceptível na quitosana modificada com anidrido sucínico. Outro fato que deve ser mencionado no espectro da quitosana modificada, na Figura 3b, é a presença das bandas em 1660 e $1625 \mathrm{~cm}^{-1}$, como resultado do desdobramento da banda principal, devido à presença de ligações intermoleculares com as moléculas da água, que ocorrem próximas a estas absorções. A primeira é influenciada pelas ligações de hidrogênio dos grupos $\mathrm{C}=\mathrm{O}$ e N-H, enquanto que a segunda está associada às ligações de hidrogênio com o grupo $\mathrm{C}=\mathrm{O}$. A região de deformação axial de 2800 a $3000 \mathrm{~cm}^{-1}$ é comum para ambos os materiais ${ }^{4,32}$. É também observada uma absorção em $2855 \mathrm{~cm}^{-1}$ no espectro da quitosana modificada, devido ao estiramento do grupo $\mathrm{CH}_{2}$, obviamente oriunda da presença do anidrido succínico.

A ressonância magnética nuclear de carbono-13 no estado sólido, que é mostrada na Figura 4, também foi usada para caracterizar os biopolímeros. O pico correspondente à carbonila em 175 pm é mais acentuado na quitina, indicando a ocorrência da desacetilação da mesma. No caso da quitosana modificada com o anidrido succínico, conforme mostra a Figura 4III, surge um conjunto de quatro picos, denominados ( $a, b, c, d)$ na região compreendida en-

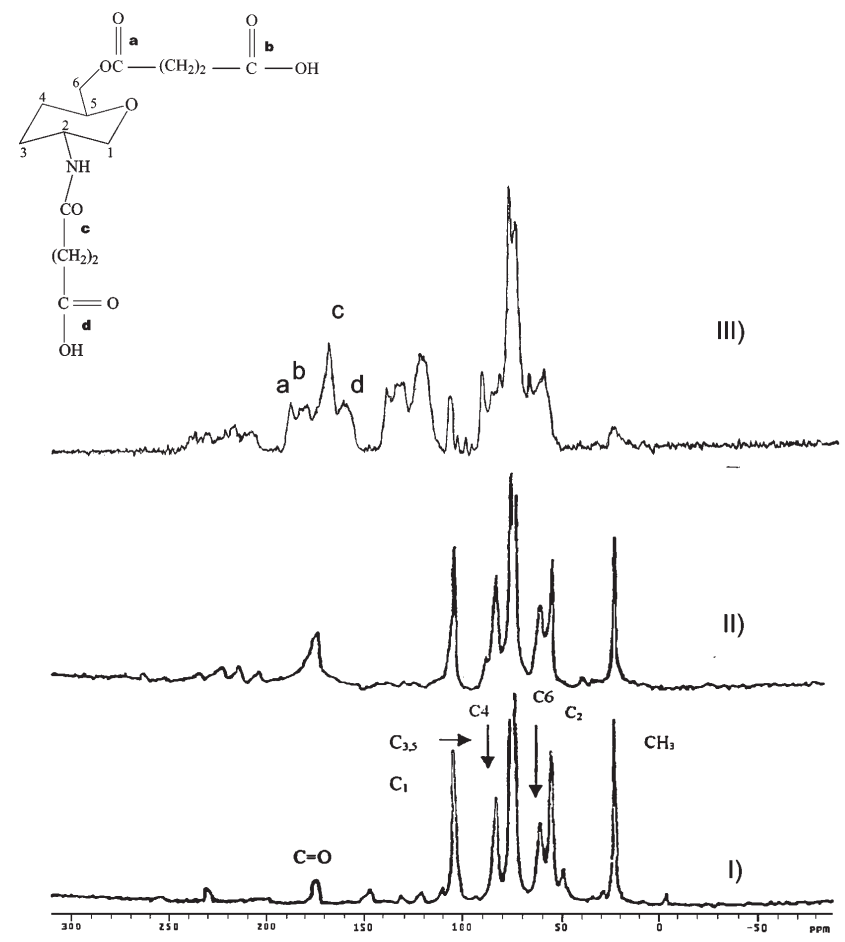

Figura 4. Ressonância magnética nuclear de carbono-13 da quitina (I), quitosana (II) e quitosana modificada com anidrido succínico (III)

tre 160 a 220 ppm referentes às carbonilas das duas moléculas imobilizadas nas posições 2 e 6 do anel glicopiranosídeo e os picos referentes aos carbonos $\mathrm{C}_{1}, \mathrm{C}_{2}, \mathrm{C}_{4}, \mathrm{C}_{6}$ e $\mathrm{C}_{3,5}$ com os deslocamentos químicos em 105, 55, 85, 60 e 75 ppm, respectivamente. Este comportamento é comum nestes tipos de materiais biopolíméricos ${ }^{33}$, sobretudo a presença do sinal em 22 ppm atribuído ao grupamento metila, cuja intensidade é diferente para quitina, quitosana e quitosana modificada.

Os valores de áreas superficiais dos adsorventes mostram que o carvão ativado é cerca de 500 vezes superior ao valor da matriz $\alpha$-Qtan2,6, como visto na Tabela 3. Tendo em mente este resultado, a priori, afasta-se a possibilidade de se considerar $\alpha$-Qtan2,6 como um material adsorvente eficiente. Entretanto, os ensaios em batelada indicam um comportamento similar de isotermas para ambos adsorventes, cujo valor de adsorção é 1,63 mmol g-1. Essa capacidade de adsorção para o carvão ativado é o dobro daquele relatado anteriormente ${ }^{34}$.

Tabela 3. Área superficial (S) da quitina ( $\alpha$-Qt), quitosana ( $\alpha$-Qtan), quitosana modificada com anidrido succínico nas posições 2 e 6 ( $\alpha$-Qtan2,6) e do carvão ativado (CA)

\begin{tabular}{lr}
\hline Compostos & $\mathrm{S} / \mathrm{m}^{2} \mathrm{~g}^{-1}$ \\
\hline$\alpha-Q t$ & 0,52 \\
$\alpha-Q \tan$ & 0,89 \\
$\alpha-Q \tan 2,6$ & 0,99 \\
$\mathrm{CA}$ & 575,84 \\
\hline
\end{tabular}

A isoterma de tempo de azul de metileno sobre quitosana, conforme a Figura 5, forma monocamada, com saturação da superfície pelas espécies adsorventes por volta de $3 \mathrm{~h}$, enquanto que a quitosana modificada e o carvão ativado atendem ao modelo de Giles, sendo visualizadas na Figura 6. Comportamento similar foi observado quando a sílica modifica quimicamente adsorveu o cátion mercúrio e os autores ajustaram ao modelo Langmuir-Freundlich ${ }^{35}$. 
As isotermas obtidas após as suspensões serem agitadas por $4 \mathrm{~h}$, para que se obtivesse o equilíbrio na interface sólido/líquido, apresentam inicialmente uma tendência de saturação para formação de um patamar, conforme mostra a Figura 7. Com esses dados é possível obter a linearização das isotermas para determinação da constante de equilíbrio $\mathrm{K}$ e da capacidade de adsorção para formação da monocamada. Contudo, surge uma nova camada, devida prova-

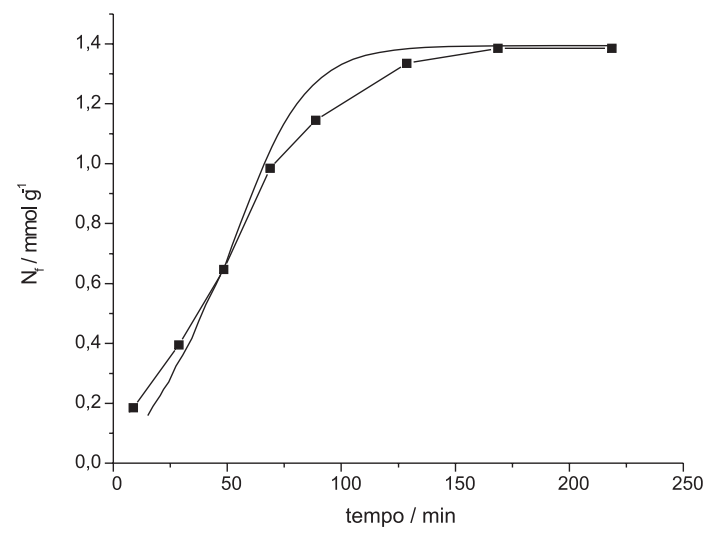

Figura 5. Isoterma-tempo de azul de metileno em quitosana (○) de concentração inicial de 5,54 $\mathrm{mmol} \mathrm{dm}^{-3}$ e isoterma-tempo normalizada (一)

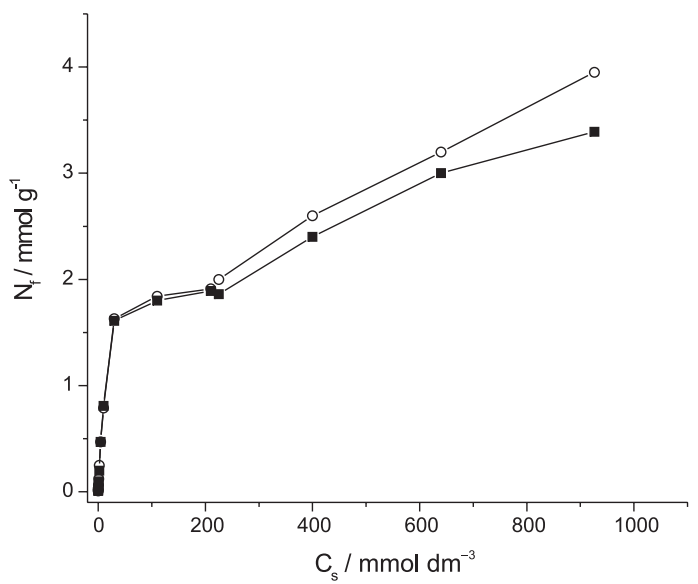

Figura 6. Processo de adsorção de azul de metileno sobre carvão ativado (○) e sobre quitosana modificada com anidrido succínico nas posições 2 e 6

(घ)

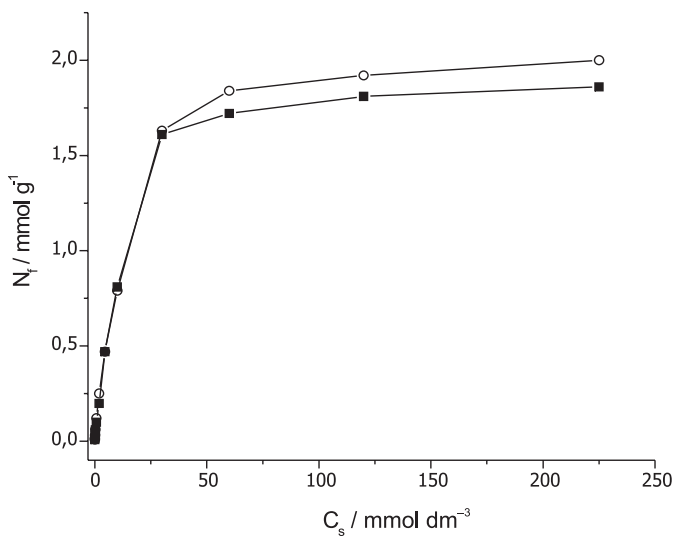

Figura 7. Isoterma de adsorção de formação de monocamada sobre carvão ativado (o) e sobre quitosana modificada com anidrido succínico nas posições velmente a efeitos interativos menos pronunciados, cujos dados se ajustam ao modelo de adsorção de Giles $^{36}$, em detrimento ao modelo de monocamada completa de Langmuir. As isotermas obtidas podem ser classificadas no sistema SSA do citado modelo, na classe L do subgrupo 3. Esses dados, segundo o modelo de adsorção, sugerem a inexistência da competição das moléculas do corante com a água, sendo que as moléculas do corante devem adsorver verticalmente ${ }^{37}$. Entretanto, o aumento da concentração próxima à superfície do adsorvente pode ocasionar a formação de agregados do azul de metileno. Uma ilustração desse fato pode ser verificada através das interações soluto-soluto em concentrações superiores a $1,0 \times 10^{-5} \mathrm{~mol} \mathrm{dm}^{-3}$, conforme a Figura 8, sendo que os espectros eletrônicos na fase líquida, com diferentes concentrações do corante, indicam a formação de dímeros. Assim, os picos em aproximadamente 610 e 660 nm referem-se às espécies diméricas e monoméricas $^{38}$, respectivamente. Esse comportamento observado para as interações soluto-soluto, que aparecem preferencialmente em solução aquosa, possivelmente pode persistir quando o corante está em presença da superfície $\alpha$-Qtan-2,6.

As titulações calorimétricas realizadas são de execução aparentemente simples e consolidadas em vários sistemas ${ }^{1,30}$, sendo aqui empregadas para se entender a interação do corante sobre Qtan2,6 , indicando a formação da monocamada em baixas concentrações do soluto. O provável início de formação de dímero é visualizado na Figura 9, conforme acontece a mudança de inclina-

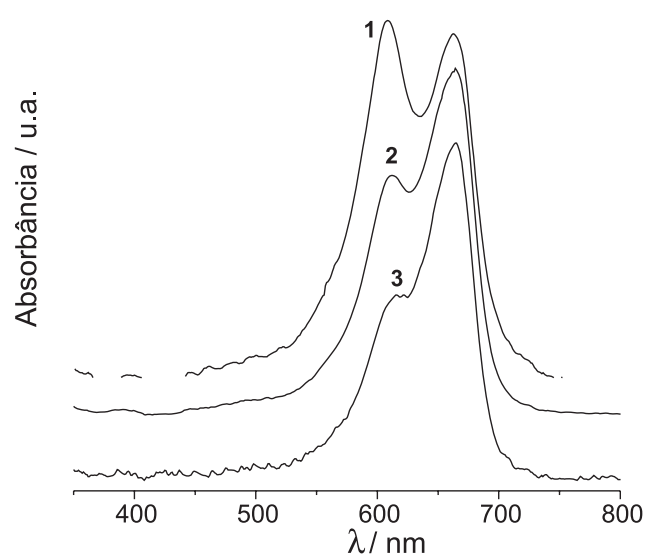

Figura 8. Espectros eletrônicos para o azul de metileno em soluções aquosas: $1=2,0 \times 10^{-4}, 2=5,0 \times 10^{-5}$ e $3=1,25 \times 10^{-5} \mathrm{~mol} \mathrm{dm}^{-3}$

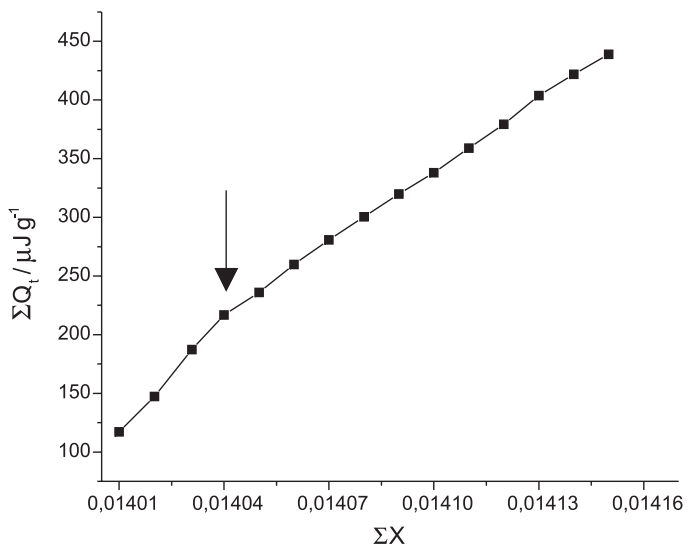

Figura 9. Titulação microcalorimétrica do azul de metileno com concentração 4,35 mmol $\mathrm{dm}^{-3}$ sobre quitosana modificada com anidrido succínico, representando os efeitos térmicos resultantes $\left(\Sigma Q_{t}\right)$ em função da fração em $\operatorname{mol}(\Sigma X)$ 
ção na representação gráfica dos dados de efeitos térmicos $(\Sigma \mathrm{Q})$ em função da fração em mol $(\Sigma X)$, devido ao aumento do corante no decorrer da titulação. Considerando-se o processo de formação da monocamada foram determinados os parâmetros termodinâmicos de adsorção. Assim, após a linearização resulta a representação mostrada na Figura 10. O coeficiente angular da reta obtida fornece a entalpia de interação da formação da monocamada ${ }^{1,30}$ com o valor $0,30 \mathrm{~J} \mathrm{~g}^{-1}$. Como esse efeito térmico refere-se à adsorção de $0,12 \mathrm{mmol}$ por um grama de quitosana modificada quimicamente, a entalpia resultante é $2,47 \pm 0,02 \mathrm{~kJ} \mathrm{~mol}^{-1}$. Através do coeficiente linear da reta obtém-se o valor da constante de equilíbrio da interação corante/quitosana modificada na interface sólido/líquido de $7350 \pm 10$. Com esse dado foi calculado o valor da energia livre de Gibbs, - 22,1 $\pm 0,2 \mathrm{~kJ} \mathrm{~mol}^{-1}$, o que indica a existência de um processo espontâneo, dando ainda um valor entrópico favorável de $66 \pm 3 \mathrm{~J} \mathrm{~mol}^{-1} \mathrm{~K}^{-1}$. No caso de formação da monocamada sobre o carvão ativado, $0,15 \mathrm{mmol}$ de corante são adsorvidos por grama da matriz, dando uma constante de equilíbrio de $5951 \pm 8$. Este processo adsorção também espontâneo reflete em um valor de energia livre de Gibbs de $-21,5 \pm 0,2 \mathrm{~kJ} \mathrm{~mol}^{-1}$.

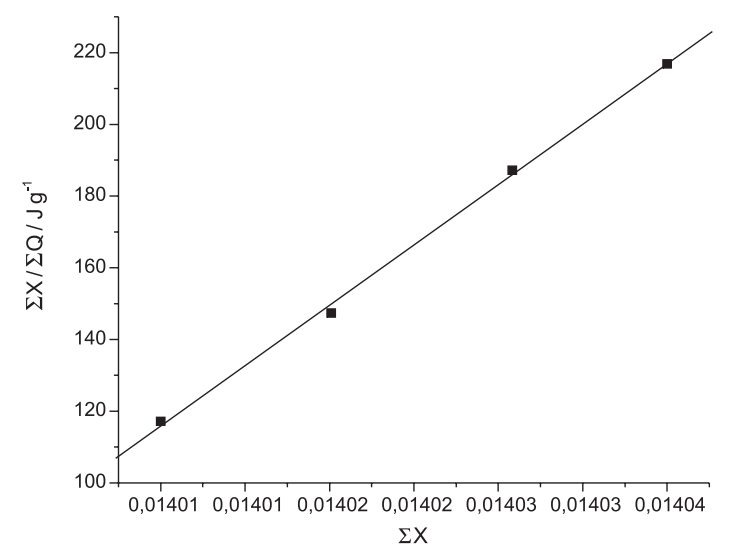

Figura 10. Linearização do primeiro trecho da isoterma de titulação microcalorimétrica do azul de metileno sobre quitosana modificada com anidrido succínico

\section{CONCLUSÕES}

Os ensaios de adsorção em batelada e por titulação calorimétrica comprovam que não ocorre a formação de uma única camada do corante azul de metileno sobre o carvão ativo e a quitosana modificada com anidrido succínico.

Os sistemas estudados foram ajustados ao modelo de Giles, o qual prediz que as isotermas obtidas são pertencentes ao sistema SSA, da classe L e do subgrupo 3, muito embora também possam ser ajustados ao modelo Langmuir-Freundlich. Através da titulação microcalorimétrica, os parâmetros termodinâmicos do processo de formação da monocamada da interação azul de metileno sobre a $\alpha$-Qtan2,6 na interface sólido/líquido ou do carvão ativado mostraram a existência de uma adsorção espontânea, representada pelos valores negativos de energia livre de Gibbs.

O novo adsorvente proposto derivado de um polissacarídeo natural mostrou-se tão eficiente quanto o carvão ativado frente à adsorção do corante azul de metileno. Os ensaios mostram que quando se usa como eluente a solução de cloreto de sódio, $97 \%$ da quantidade do corante podem ser removidos do suporte $\alpha$-Qtan2,6, enquanto que no carvão ativo são recuperados apenas $42 \%$. Além da eficiência de remoção, este material tem a vantagem em ser barato, não tóxico, biocompatível e biodegradável.

\section{AGRADECIMENTOS}

Ao suporte financeiro da CAPES e FAPESP.

\section{REFERÊNCIAS}

1. Monteiro Jr, O. A. C.; Airoldi, C.; J. Colloid Interface Sci. 2005, 282, 32.

2. Vieira, E. F. S.; Simoni, J. A.; Airoldi, C.; J. Mater. Chem. 1997, 7, 2249.

3. Kumar, M. N. V. R.; Muzzarelli, R. A. A.; Muzzarelli, C.; Sashiwa, H.; Domb, A. J.; Chem. Rev. 2004, 104, 6017.

4. Lima, I. S.; Airoldi, C.; Themochim. Acta 2004, 421, 133.

5. Lima, I. S.; Airoldi, C.; Colloids Surf., A 2003, 229, 129.

6. Grant, S.; Blair, H. S.; Mckay, G.; Polym. Comm. 1990, 31, 267.

7. Badawy, M. E. I.; Rabea, E. I.; Rogge, T. M.; Stevens, C. V.; Smagghe, G.; Steurbaut, W.; Hofte, M.; Biomacromolecules 2004, 5, 589.

8. Kurita, K.; Mori, S.; Nishiyama, Y.; Harata, M.; Polym. Bull. 2002, 48, 159.

9. Shigemasa, Y.; Ishida, A.; Sahiwa, H.; Saimoto, H.; Okamoto, Y.; Minami, S.; Matsuhashi, A.; Chem. Lett. 1995, 623.

10. Shigemasa, Y., Ishida, A., Sahiwa, H., Saimoto, H., Okamoto, Y.; Minami, S., Matsuhashi, A.; Chem. Lett. 1995, 1, 1623.

11. Xu, J.; McCarthy, S. P.; Gross, R. A.; Macromolecules 1996, 29, 3436.

12. Monteiro Jr, O. A.C.; Airoldi, C.; Int. J. Biol. Macromol. 1999, $26,119$.

13. Rhazi, M.; Desbrières, J.; Tolaimate, A.; Rinaudo, M.; Vottero, P.; Alagui, A.; Polymer 2002, 43, 1267.

14. Cervera, M. L.; Arnal, M. C.; Guardia, M.; Anal. Bioanal. Chem. 2003, 375,820 .

15. Anjos, F. S. C.; Vieira, E. F. S.; Cestari, A. R.; J. Colloid Interface Sci. 2002, 253, 243.

16. Ribeiro, E. S.; Rosatto, S. S.; Gushikem, Y.; Kubota, L.T.; J. Solid State Electrochem. 2003, 7, 665.

17. Kurita, K.; Polym. Degrad. Stab. 1998, 59, 117.

18. Engene, K.; Lim, L. Y.; Biomaterials 2003, 24, 2339.

19. Okamoto, Y.; Nose, M.; Miyatake, K.; Sekine, J.; Oura, R.; Shigemasa, Y.; Minami, S.; Carbohydr. Polym. 2000, 44, 211.

20. Muzzarelli, R. A. A.; Weckx, M.; Fillipini, O.; Carbohydr. Polym. 1989, 11, 293.

21. Papineau, A. M.; Hoover, D. G.; Knorr, D.; Farkas, D. F.; Food Biotechnol. 1991, 5, 45 .

22. Minamisawam H.; Arai, N.; Okutani, T.; Anal. Sci. 1995, 11, 961.

23. Gotoh, T.; Matsushima, K.; Kikuchi, K-I.; Chemosphere 2004, 55, 135.

24. Ngah, W. S. W.; Musa, A.; J. Appl. Polym. Sci. 1998, 69, 2305.

25. Xu, C.; Cai, H.; Xu, Q.; He, P.; Fang, Y.; Fresenius J. Anal. Chem. 2001, $369,428$.

26. Darder, M.; Colilla, M.; Ruiz-Hitzky, E.; Chem. Mater. 2003, 15, 3774.

27. Savant, V. D.; Torres, J. A.; Biotechnol. Prog. 2000, 16, 1091.

28. Sales, J. A. A.; Airoldi, C.; Thermochim. Acta 2005, 427, 77.

29. Critter, S. A. M.; Freitas, S. S.; Airoldi. C.; Thermochim. Acta 2004, 417, 275.

30. Al-Asheh, S.; Banat, F.; Saeidi, R.; Adsorpt. Sci. Technol. 2003, 21, 189.

31. Lima, I. S.; Tese de Doutorado, Universidade Estadual de Campinas, Brasil, 2005.

32. Sabnis, S.; Block, L. H.; Polym. Bull. 1997, 1, 67.

33. Heux, L.; Brugnerotto, J.; Desbrières, J.; Versali, M. F.; Rinaudo, M.; Biomacromoles 2000, 1, 746.

34. Lin, Y.; Teng, H.; Microporous Mesoporous Mater. 2002, 54, 167.

35. Antochshuk, V.; Olkhovyk, O.; Jaroniec, M.; Park, I.; Ryoo, R.; Langmuir 2003, 19, 3031 .

36. Giles, C. H.; MacEwan, T. H.; Nakhwa, S. N.; Smith, D.; J. Chem. Soc. 1960, 1, 3973.

37. Kurokama, Y.; Ohta, H.; Okubo, M.; Takahashi, M.; Carbohydr. Polym. 1994, 23, 1.

38. Antonov, L.; Gergov, G.; Petrov, V.; Kubista, M.; Nygren, J.; Talanta 1999, $49,99$. 